\section{World Politics (WP)}

1973. Leader, Shelah Gilbert. The Emancipation of Chinese Women. 26(1): 55-79.

1974-75. Simmons, Ruth, George B. Simmons, B. D. Misra, Ali Ashraf. Organizing for Government Intervention in Family Planning. 27(4): 569-96.

1982. Jaquette, Jane S. Women and Modernization Theory: A Decade of Feminist Criticism. 34(2): 267-84.

\section{Notes}

*We would like to thank Arizona State University's Arts/Social Science/Humanities grant program and the School of Justice Studies for the funding they provided for the project "The Current State of the Field of Women and Politics," of which this paper is a part.

1. See Ivor Crewe and Pippa Norris. 1991. "British and American Journal Evolution: Divergence or Convergence?" PS: Political Science \& Politics 24(3): 524-31. Crewe and Norris studied 74 journals that political scientists frequently read. Since our intent is to assess the state of research about women in political science, we examined 15 of their top 18 journals, excluding three journals whose foci lie outside the discipline: The American Journal of Sociology, American Sociological Review, and Daedalus.
2. We have studied articles about women. Our bibliography only partially overlaps, but is distinct from the set of articles written by women.

3. Polity is more like the journals in Cluster $\mathrm{C}$ in its decade of first publication, patterns of article publication, time-frame when the majority of articles appeared, and journal audience, and hence was placed in that category. The content of $P A R$ articles more closely resembles the content of articles in Cluster D, and thus was included in that cluster.

4. Compared with the top 15 journals, Women \& Politics contains roughly the same total number of articles on topics commonly identified as "women's issues," including alimony, abortion, child care, domestic violence, the Equal Rights Amendment, rape, and sexual harassment. $W \& P$ has also published 68 articles discussing feminism and feminist theory, compared with 30 such articles in the set of 15 . Additionally, $W \& P$ considers topics which have been virtually ignored in the top 15 journals: women and aging; women's health care; women scientists and the treatment of women in scientific research; and lesbian literature. More importantly, $W \& P$ authors acknowledge female theorists nearly ignored in other political science journals, including Luce Irigaray, Simone de Beauvoir, and Carol Gilligan. For a more detailed analysis of the contributions of $W \& P$, see Rita Mae Kelly, Linda $\mathrm{M}$. Williams, and Kimberly Fisher, "Women \&
Politics, An Assessment of Its Role Within the Discipline of Political Science," forthcoming.

5. The references cited after each of the general knowledge statements are only examples of some of the articles addressing each topic. An exhaustive list would render this article too long for publication in PS. The articles referenced from our study appear in the complete bibliography of all study articles following this article.

6. Reports of the APSA Committee on the Status of Women in the Profession represent 31 of the total 82 pieces on women in PS.

\section{About the Authors}

Rita Mae Kelly chairs the School of Justice Studies at Arizona State University. She is the recipient of the Distinguished Research Award of the American Society for Public Administration (1991), a Fulbright Fellowship Award to Brazil (1991), and the Outstanding Mentor in the Discipline Award, given by the Women's Caucus of Political Science (1991).

Kimberly Fisher is pursuing an M.Phil. in Sociology of Gender at the University of Essex on a Marshall Scholarship. She received her M.S. in Justice Studies at Arizona State University.

\title{
Correlates of Publication Success: Some AJPS Results
}

\author{
Michael S. Lewis-Beck, University of Iowa \\ Dena Levy, University of Iowa
}

\begin{abstract}
Publication in the American Journal of Political Science (AJPS) is highly valued, largely because of the journal's scholarly reputation. In a recent survey, $A J P S$ placed second among general political science journals. [Looking at their top 20 social science journals, American political scientists gave the following quality ranking, from No. 1 to No. 6: World Politics, American Sociological Review, American Political Science Review, American Journal of Sociology, AJPS, Journal of Politics; see Crewe and Norris (1991, 525, Table 1).] This reputation for quality helps account for the great number of submissions (an annual average of about 265 papers, for the years 1991-92).
\end{abstract}

Of these submissions, only about one in ten receives initial acceptance (another one in ten receives a reviseand-resubmit, the remaining eight a rejection). Despite these heavy odds against acceptance, some authors overcome them. What predicts publication success in AJPS? Below, we assess what does not help predict it, and what does. These findings, we conclude, lay bare "the paradox of editorship."

\section{Poor Predictors of Manuscript Acceptance}

The following five hypotheses are commonly advanced for publication success.
H1: Past Success. (Those who published before are much more likely to be accepted again.)

$\mathrm{H} 2$ : Field. (Certain fields such as American Politics are favored; certain others such as Political Philosophy are not favored.)

H3: School. (Scholars from prestige schools do better.)

H4: Timing. (The volume of submissions is cyclical, so submission in heavy seasons works against acceptance.)

H5: Turnaround. (The faster the decision letter comes back, the more likely it will be a rejection.)

To test H1, on Past Success, we 
gathered authorship data on $A J P S$ articles $(\mathrm{N}=545)$ published from 1974-92. We found that the overwhelming majority (70\%) of authors (defined as the only, or first, author) failed to publish again in $A J P S$. Moreover, among the 165 authors who got a paper accepted another time, the bulk of them (102) appeared only once more across the 19-year period. At the high end, just 11 authors had more than four publications, 1974-92. Obviously, past success does not give you "a lock on it." On the contrary, a naive prediction would be that, if you have published in $A J P S$, you probably will not repeat that performance. More realistically, these data on recidivism merely point up the highly competitive market.

To test our other hypotheses, we analyzed data from a current (1991-92) sample $(\mathrm{N}=323)$ of $A J P S$ manuscript submissions. Consider $\mathrm{H} 2$, the Field hypothesis. Papers were classified according to whether they were in Political Philosophy, Formal Theory, Methodology, Public Policy, Comparative Politics, American Politics, International Relations, or Political Psychology. Percentage differences in rejection rates across six of these eight fields were generally trivial-from $71 \%$ to $83 \%$. Rejection rates outside (and below) this range were found for Political Philosophy (57\%) and Methodology $(42 \%)$, implying that these areas are more likely to have success. However, this implication is misleading; the cell entries are too small (8 and 10 , respectively) to infer that these are favored specialties. Rather, the overall conclusion is that papers from different fields fare about equally.

With respect to $\mathrm{H3}$, the School hypothesis, there is a small correlation $(r=.17)$ between author affiliation with a Top 20 Political Science Department ( $0=$ no, $1=$ yes $)$ and editorial decision $(-1=$ reject, $0=$ revise and resubmit, 1 = accept). (We reviewed Ph.D.-granting institutions, and assigned a top 20 rank on the basis of the scholarly quality of the political science faculty and graduate program.) This correlation suggests, as expected, that the quality of the department makes some difference. (This would be the expectation, if only because of the greater research resources available to those in Top 20 programs.) However, what is noteworthy is how little difference it makes.

With regard to $\mathrm{H} 4$, on Timing, there might be a little seasonality. At the extremes, $27 \%$ of the papers submitted in the fall $(N=64)$ received a revise-and-submit or an acceptance, whereas in the spring $(\mathrm{N}=117)$, the comparable figure was just $17 \%$. Still, this ten percentage point difference is not statistically significant at conventional levels. In reality, an author submitting in any season would face odds that were essentially the same.

Finally, we address H5, on Turnaround. With these 1991-92 submis-

.. a naive prediction would be that, if you have published in AJPS, you probably will not repeat

\section{that performance.}

sions, authors received a decision, on average, just under two-and-a-half months after the manuscript was logged in at the Iowa office. (The standard deviation around that value was one month.) When turnaround time (in months) is correlated with editorial decision, $\mathrm{r}=.02$, there is virtually no linear relationship. Thus, for the expectant author, early news should not be considered more likely to be bad (or good) than later news.

\section{Good Predictors of Manuscript Acceptance}

The data lend little support for the foregoing five hypotheses on publication success. However, two remaining hypotheses receive considerable support.

\section{H6: Reviewer Evaluations. (The reviewers really liked my paper.)}

H7: Editor Evaluation. (The editor really liked my paper.)

Along with the manuscript itself, the substantive comments of review- ers are the stuff from which the editorial decision is made. In addition to providing extensive written comments, each reviewer is asked to fill out the "AJPS Manuscript Rating Form." (These forms do not go to authors.) These ratings may provide a partial, quantitative assessment useful for testing H6. The reviewer rates the quality of the manuscript on the following items:

1. Publish Scale. "Please rate the manuscript on the following scale. A mark at the left-hand extreme (a score of " 0 ") indicates that you definitely would not want to see the manuscript published in AJPS. A mark at the right-hand extreme (a score of "10") indicates that you definitely would want to see the manuscript published in AJPS. A score of " 5 " is in the middle of the scale and indicates that your feelings are neutral."

2. Breadth. "Considering breadth of appeal to political science scholars, how would you rate this manuscript?" Broad, middling, or narrow.

3. Contribution. "Different works contribute to the advancement of scientific knowledge in different ways. Overall, please rate the contribution of this paper." High, medium, low, or none.

4. Vote. "If you were forced to decide a simple 'yes' or 'no' with regard to publication of this manuscript in $A J P S$, how would you vote?" yes, or no.

We expect these rating scores to reflect, strongly if imperfectly, the assessments in the reviewer's extended substantive comments on the manuscript. Therefore, since the editor relies on these substantive comments, we also would expect actual editorial decision outcomes naturally to correlate strongly with these ratings. And they do. That is, for Publish Scale, $r=.54$; Contribution, $\mathrm{r}=.52$; Advice, $\mathrm{r}=.51$; Breadth, $r=.29$. Let us explore the first three, the strongest correlates, in more detail.

With regard to the Publish Scale (the $0-10$ point rating), once papers pass the " 7 " mark (an average over the usual three reviewers), the 
chances are better than 50-50 that the paper receives either an accept or a revise-and-resubmit. At the other end, if the paper rates no more than a " 3 ," chances are about $90 \%$ or better that it is to be rejected. Similarly, with the Contribution variable, $53 \%$ of those scoring "high" were accepted, while none of the papers scoring "none" were accepted. This is strong evidence that, as we had expected, reviewers' opinions make an important difference.

The impact of reviewer opinion is seen clearly in Table 1, where the last variable, reviewer "yes" or "no" vote on publication, is related to editorial decision. On the one hand, when reviewers collectively judged that the paper rated a rejection, that was the actual decision $89.7 \%$ of the time. On the other hand, when reviewers judged that the paper should be accepted, that corresponded to an acceptance, or at least a revise-and-resubmit, $54.5 \%$ of the time.

\section{TABLE 1}

Editorial Decision by Rating Sheet

Vote, * AJPS Manuscripts, 1991.92

\begin{tabular}{lcc}
\hline & Rating Sheet Vote \\
\hline Decision & Reject & Accept \\
\hline Reject & $89.7 \%$ & $45.5 \%$ \\
Revise and Resubmit & 6.6 & 20.0 \\
Accept & 3.8 & 34.5 \\
& $100 \%$ & $100 \%$ \\
(N) & $(213)$ & $(110)$
\end{tabular}

For each paper, the responses to the dichotomous vote item (see text, "yes" accept; "no"" = reject) were averaged for the (typically) three reviewers, giving a single vote score for each paper. (If the average was less than .5 , then it was coded ' 0 " for the paper as a whole; if the average was .5 or more, then it was coded " 1 " for the paper as a whole.)

As potent as reviewer opinion is, the table implies that it is not invariably followed. Most notably, $45.5 \%$ of the papers where, on balance, the reviewers voted "yes" were actually rejected. This finding lends support to $\mathrm{H} 7$, suggesting the editor may exercise some independent judgment. It is tempting to take a normative stance on this issue-should an editor exercise his or her own judgment? For the editor, however, this independence is foremostly practical, due to the exigencies of page restrictions.

The marginals of Table 1 reveal the practical problem. If the editor always followed reviewer advice, as captured in this particular measure, that would mean acceptance of one out of three papers. (That is, overall the vote was to publish 110 of these 323 papers. This advice is not an artifact of the "forced choice" nature of the vote item. Similar advice is given if we count as an "accept recommendation" an

. . . the AJPS editor, like the editors of other major political science journals, is forced by page constraints alone to make yet another quality cut through the papers,
reading over the reviews
and manuscripts again
before making a final
decision.

average value on the 0-10 Publish Scale variable of 6 or greater.) Each issue, then, would be about triple in size, and costs would multiply accordingly. Obviously, nowhere near that much journal space is likely to become available soon. Thus, the AJPS editor, like the editors of other major political science journals, is forced by page constraints alone to make yet another quality cut through the papers, reading over the reviews and manuscripts again before making a final decision.

\section{Conclusion}

Reviewer opinion, as expected, is a good predictor of publication success at $A J P S$. In following reviewer advice, the editor acts as a "delegate," making decisions on the basis of constituency opinion. However, the editor cannot act solely as a "delegate" of the reviewers. First, reviewers are only part of the con- stituency. (Besides, there are journal readers, Midwest Association members, researchers, and students, many of whom may not do reviews.) Second, even if reviewers are considered the primary constituency, the standard sample of three reviewers per paper cannot be counted on to estimate perfectly the opinion parameter in the reviewer population. (No matter how carefully the editor sifts substantive reviewer comments, the tiny $\mathrm{N}$ problem persists. And, significantly increasing the number of reviewers poses its own difficulties.) Third, supposing reviewer opinions were representative estimates, the journal's space constraints demand that the editor exercise independent judgment. In exercising this independence, the editor acts as a "trustee," carrying out decisions under the burden of responsibility the term implies. [Of course, in the political science literature, the "delegatetrustee" distinction can be traced back to the classic of Wahlke et al. (1962).]

There is, then, a "paradox of editorship." On the one hand, an editor serves as a reviewer "delegate," on the other, as a "trustee" for the larger political science community. As we have seen, these two roles do not always pull the editor in the same direction. [The recent $A J P S$ paper by Sigelman et al. (1992) nicely articulates this paradox at the level of elected officials.] Whether the paradox finds a satisfactory collective resolution seems to depend, ultimately, on the quality of the decisions made. That is to say, how good are the papers that are published? The measurement of publication quality is no easy task. However, AJPS supporters should take heart, for the journal consistently performs at or near the top of the various quality ratings that have been conducted. [In addition to the recent Crewe and Norris (1991), see Garand (1990), Giles et al. (1989), and Lester (1990).]

\footnotetext{
References

Crewe, Ivor, and Pippa Norris. 1991. "British and American Journal Evaluation: Divergence or Convergence?" PS: Political Science \& Politics 24(3): 524-31. Garand, James C. 1990. "An Alternative
} 
Interpretation of Recent Political Science Journal Evaluations." PS: Political Science \& Politics 23(3): 448-51.

Giles, Micheal, Francie Mizell, and David Patterson. 1989. "Political Scientists' Journal Evaluation Revisited.' PS: Political Science \& Politics 22(3): 613-17.

Lester, James P. 1990. "Evaluating the Evaluators: Accrediting Knowledge and the Ranking of Political Science Jour- nals." PS: Political Science \& Politics 23(3): 445-47.

Sigelman, Lee, Carol K. Sigelman, and Barbara J. Walkosz. 1992. "The Public and the Paradox of Leadership: An Experimental Analysis." American Journal of Political Science 36(May): 366-85.

Wahlke, John C., Heinz Eulau, William Buchanan, and Leroy Ferguson. 1962. The Legislative System. New York: Wiley.

\section{About the Authors}

Michael S. Lewis-Beck is a professor, department of political science, University of Iowa. He is the editor of the American Journal of Political Science.

Dena Levy is an editorial assistant for the American Journal of Political Science. 